Energy Research Journal 1 (2): 171-175, 2010

ISSN 1949-0151

(C) 2010 Science Publications

\title{
Effect of Length Ratios on Heat Transfer Characteristics of Closed-Loop Oscillating Heat Pipe with Non-Uniform Diameter
}

\author{
P. Sakulchangsatjatai, P. Pathike and P. Terdtoon \\ Department of Mechanical Engineering, Faculty of Engineering, \\ Chiang Mai University, Thailand 50200
}

\begin{abstract}
Problem statement: Closed-loop oscillating heat pipe is a high performance heat exchanger especially as this heat exchanger has one direction flow of working fluid inside tube. Approach: This research studies the effect of length ratios on heat transfer characteristic of Closed Loop Oscillating Heat Pipe with Non-Uniform Diameter (CLOHP/NUD). The 2.03 and $1.06 \mathrm{~mm}$ inner diameter of capillary tube were alternated connection and bent into 16 turns and both ends were connected to form of loop. Length ratio of 3, 1, 0.33 and 0.2 were studied. Evaporator, adiabatic and condenser length were $100 \mathrm{~mm}$. R123, ethanol and water were used as the working fluid and filling ratio $50 \%$ by total inner volume of CLOHP/NUD was used. The evaporator and condenser temperatures were controlled at 100 and $20^{\circ} \mathrm{C}$. CLOHP/NUD operated at vertical plane. Results: It was found that, the CLOHP/NUD transferred higher heat than the conventional Closed Loop Oscillating Heat Pipe (CLOHP) with the same heat transfer area because the working fluid flowed in only one direction. Working fluid moved to condenser section in larger inner diameter and returned to evaporator section in smaller inner diameter. The heat flux of the CLOHP/NUD with R123 as working fluid increased from $15.49-20.85 \mathrm{~kW} \mathrm{~m}^{-2}$ when length ratio decreased from 1-0.2, respectively. This is due to the head loss from the sudden enlargement resulted in well circulation of working fluid. Furthermore, higher heat flux was obtained by using water as working fluid. Conclusion: The heat transfer performance of CLOHP/NUD can be improved if one directional circulation of working fluid can be induced.
\end{abstract}

Key words: Closed loop oscillating heat pipe, non-uniform diameter, length ratios, heat transfer characteristics

\section{INTRODUCTION}

Heat pipe is a high performance heat exchanger and useful device in engineering field such as a heat exchanger to recover waste heat energy, removing of local heat and heat in electronic device. The heat pipe has been accepted as a necessary part for sustainable well-being. Heat pipe has many advantages. One type of heat pipe is a Close-Loop Oscillating Heat Pipe (CLOHP) (Akachi et al., 1996). CLOHP is small, light weight, simple structure, high efficiency, fast thermal responsibility, performing through low difference of temperature and it can be operate in all orientation. In many researches, CLOHP had shown its higher performance because inside working fluid flowed in one direction (Khandekar and Groll, 2004; Chareonsawan et al., 2003). Close Loop Oscillating Heat Pipe with Check Valve (CLOHP/CV) has been proposed to controlled working fluid circulation in one direction, it had higher performance at higher ratio of number of turns to number of check valve (Rittidech et al., 2007). Moreover, the other type of close loop oscillating heat pipe with controlled flow direction is Closed Loop Oscillating Heat Pipe with NonUniform Diameter (CLOHP/NUD). CLOHP/NUD can control flow direction by their geometry. It has higher performance than CLOHP (Liu et al., 2007; Tharawadee et al., 2008). However, few previous researchers studied only effect of diameter ratio. In this research, thus, the structure was changed by changing length of connected tube in order to study of effects of length ratio (length of $2.03 \mathrm{~mm}$ tube by length of 1.06 $\mathrm{mm}$ tube) and working fluid to heat transfer characteristics of CLOHP/NUD operated at vertical position.

\section{MATERIALS AND METHODS}

Experimental setups and procedure: The CLOHP/NUD set-up used in this study was made of

Corresponding Author:P. Sakulchangsatjatai, Department of Mechanical Engineering, Faculty of Engineering, Chiang Mai University, Thailand 50200 Tel: +66-53-944144/ext.911 Fax: +66-53-226014 
2.03 and $1.06 \mathrm{~mm}$ inner diameter of copper capillary tube alternated connection and bent into 16 turns. Both ends were connected in a form of loop. Evaporator, adiabatic and condenser length were $100 \mathrm{~mm}$. Length ratio of $3,1,0.33$ and 0.2 were studied. The shorter tube length was control as $300 \mathrm{~mm}$ as shown in Fig. 1.

CLOHP/NUD was evacuated and then working fluid was filled with the filling ratio of $50 \%$ by total inner volume. R123, ethanol and water were used as the working fluid. The experimental set-up is shown in Fig. 2. The heating silicone oil from a hot bath (HAAKE, 8N3-B and $\pm 0.5^{\circ} \mathrm{C}$ accuracy) was circulated and maintained the inlet temperature at $100^{\circ} \mathrm{C}$.

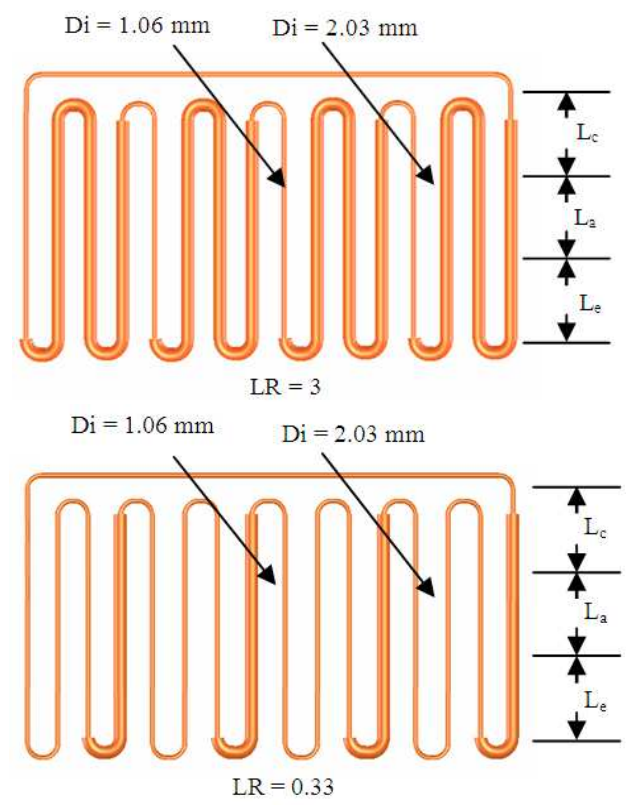

Fig. 1: CLOHP/NUD

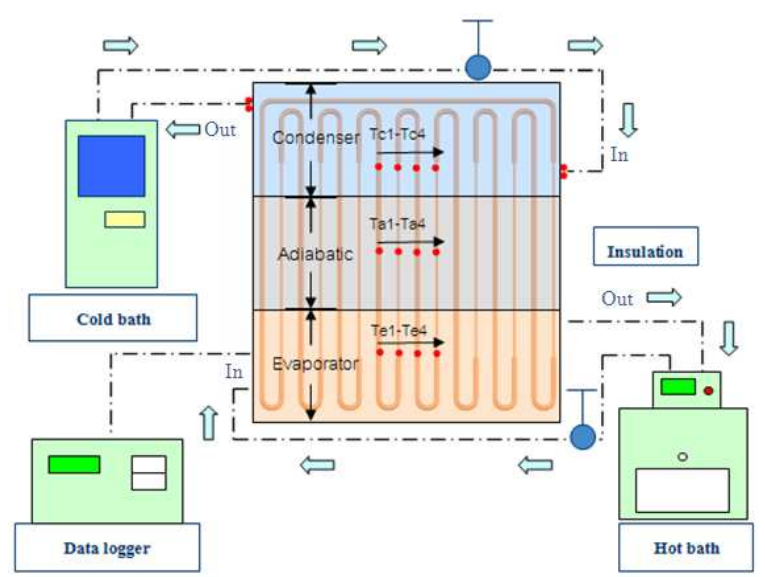

Fig. 2: Details of the experimental set-up
The cooling water from a cold bath (BITZER, D7032 and $\pm 1^{\circ} \mathrm{C}$ accuracy) was circulated and maintained the inlet temperature at $20^{\circ} \mathrm{C}$. The mass flow rate of cooling water was measured by a balance (Computer electronic scale $\pm 0.005 \mathrm{~kg}$ ). The temperature at specified points was monitored by a data logger (Brainchild, VR18, accuracy $\pm 0.1{ }^{\circ} \mathrm{C}$ ). Chromelalumel thermocouples (Omega-type ' $\mathrm{K}$ ') were used to measure the temperature of the cooling water, by two probes were installed at the inlet and outlet cooling water of the condenser. The heat transfer was calculated by calorimetric method at condenser section. In addition, the 12 thermocouples were employed to measure the temperature at 4 points in evaporator section, 4 points at adiabatic section and 4 points in condenser section. All test sets were wellinsulated with foam insulation (Armaflex, 3/8 inch thickness).

The inlet temperature of the hot baths and cold baths were controlled at 100 and $20^{\circ} \mathrm{C}$, respectively. The hot and cold fluids were supplied to the jackets of both the evaporator and condenser sections, respectively. After a quasi-steady state was reached, the temperature and flow rate were recorded and then the heat throughput was determined. Each experiment was repeated for three times. Finally, the influenced parameters were varied according to the required objectives.

\section{RESULTS}

The measured temperature of CLOHP/NUD operating at normal state (length ratios $0.33, \mathrm{~L}_{\mathrm{e}}=\mathrm{L}_{\mathrm{a}}$ $=\mathrm{L}_{\mathrm{c}}=100 \mathrm{~mm}$, alternative of 2.03 and $1.06 \mathrm{~mm}$ inner diameter of CLOHP/NUD, 16 turns, filling ratio 50\%, vertical orientation ) using R123, ethanol and water as working fluid are shown in Fig. 3-5, respectively.

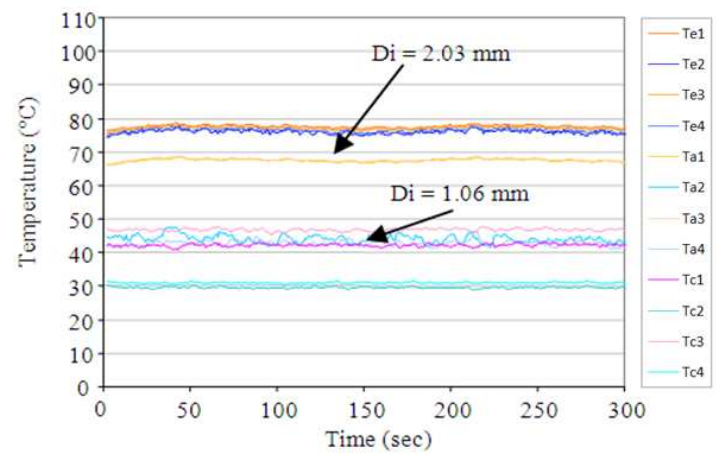

Fig. 3: The measured temperature of CLOHP/NUD (LR of 0.33 and R123 as working fluid) 
Energy Rec. J. 1 (2): 171-175, 2010

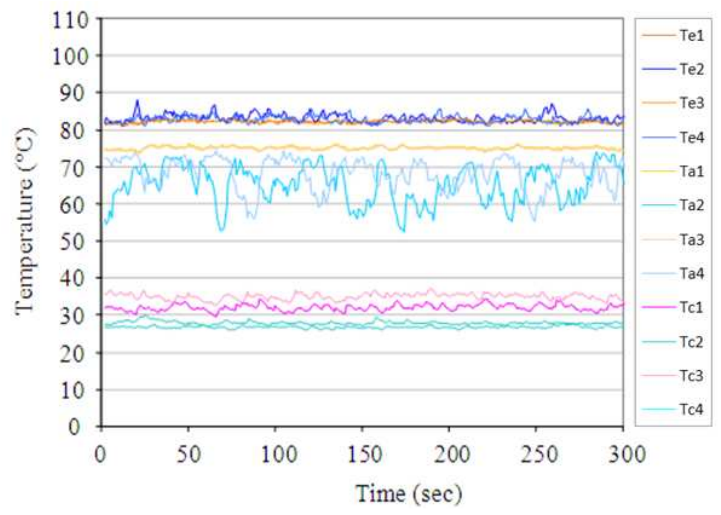

Fig. 4: The measured temperature of CLOHP/NUD (LR of 0.33 and ethanol as working fluid)

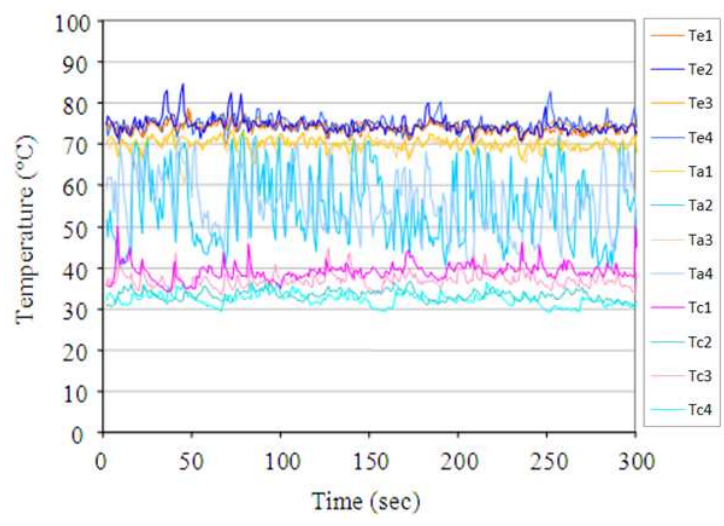

Fig. 5: The measured temperature of CLOHP/NUD (LR of 0.33 and water as working fluid)

Figure 6 shows the heat flux of CLOHP/NUD with R123, ethanol and water as working fluid at the condition of length ratios $0.33, \mathrm{~L}_{\mathrm{e}}=\mathrm{L}_{\mathrm{a}}=\mathrm{L}_{\mathrm{c}}=100 \mathrm{~mm}$, alternative of 2.03 and $1.06 \mathrm{~mm}$ inner diameter of CLOHP/NUD, 16 turns, filling ratio 50\%, vertical orientation. The highest heat flux is obtained at $21.79 \mathrm{~kW} \mathrm{~m}^{-2}$ when using water as working fluid while R123 and ethanol provide the heat flux at 20.16 and $14.14 \mathrm{~kW} \mathrm{~m}^{-2}$, respectively.

Figure 7 and 8 show the relationship of heat flux of CLOHP/NUD $\left(\mathrm{L}_{\mathrm{e}}=\mathrm{L}_{\mathrm{a}}=\mathrm{L}_{\mathrm{c}}=100 \mathrm{~mm}\right.$, alternative of 2.03 and $1.06 \mathrm{~mm}$ inner diameter of CLOHP/NUD, 16 turns, filling ratio $50 \%$, vertical orientation ) and length ratios, when R123 and water were use as working fluid, respectively. In Fig. 7, R123 was use as working fluid at vertical plane, the highest heat flux of CLOHP/NUD with 0.2 length ratio is $20.85 \mathrm{~kW} \mathrm{~m}^{-2}$. Which it was higher than CLOHP/NUD with length ratio of 1 about $34.60 \%$

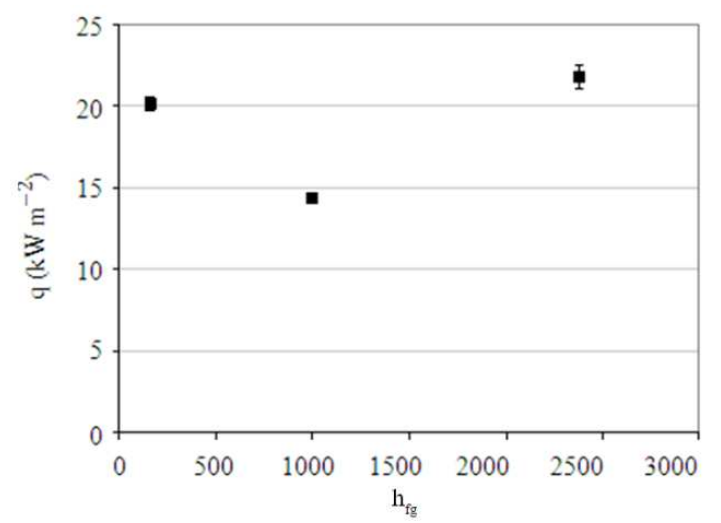

Fig. 6: Effect of working fluids on heat transfers characteristic of CLOHP/NUD (LR of 0.33)

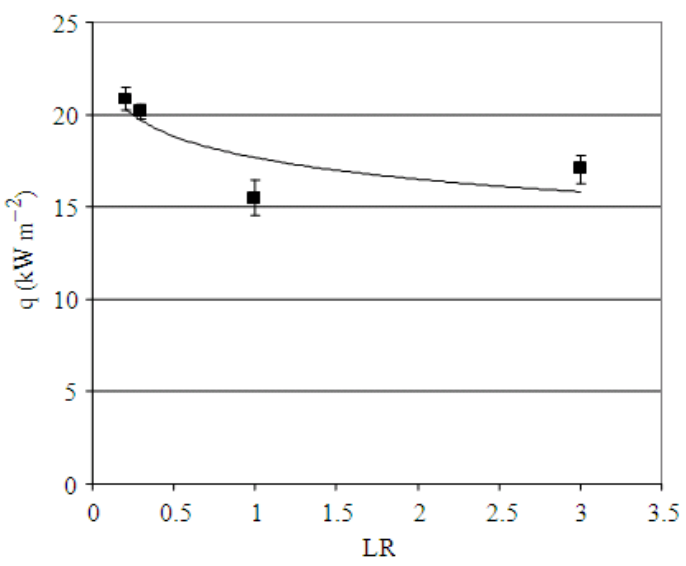

Fig. 7: Effect of length ratios on heat transfers characteristic of CLOHP/NUD (R123 as working fluid)

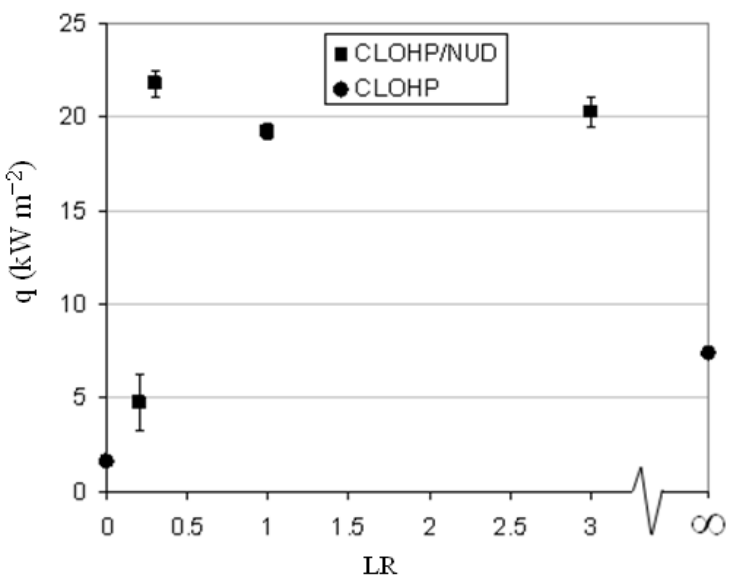

Fig. 8: Effect of length ratios on heat transfers characteristic of CLOHP/NUD (water as working fluid) 


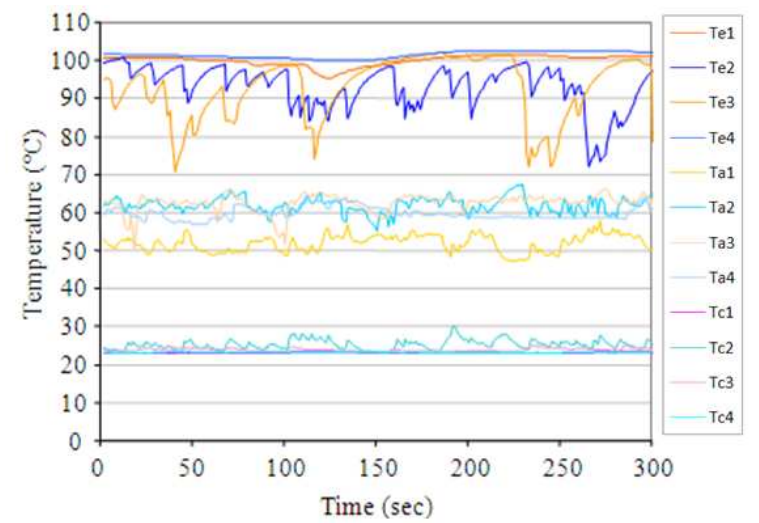

Fig. 9: The measured temperature of CLOHP/NUD (LR of 0.2 and water as working fluid)

Figure 9 shows temperature of CLOHP/NUD operating at critical state (length ratios of $0.2, \mathrm{~L}_{\mathrm{e}}=\mathrm{L}_{\mathrm{a}}$ $=\mathrm{L}_{\mathrm{c}}=100 \mathrm{~mm}, 2.03$ and $1.06 \mathrm{~mm}$ inner diameter of CLOHP/NUD, water was use as working fluid, 16 turns, filling ratio $50 \%$, vertical orientation

\section{DISCUSSION}

CLOHP/NUD operation: The measured temperatures are shown in Fig. 3-5, it was implied that temperature at adiabatic section of larger diameter tube is higher than that of smaller diameter tube. CLOHP/NUD is heated at evaporator section, resulting in the vapor is easily circulated inside the larger diameter tube. After that, the working fluid flows throughout adiabatic section resulting in the temperature of adiabatic section with larger diameter was higher. This high temperature tube will be called "hot tube" afterward. Then, the working fluid flows inside condenser section and condenses. The condensate flows inside smaller diameter tube and flows throughout adiabatic section, resulting in the temperature of adiabatic section of smaller diameter tube was lower than temperature in larger diameter tube. This will designated as "cold tube". The working fluid returns into evaporators to complete it circulation in one direction.

Effect of working fluids: Figure 3-5 show that adiabatic section of $2.03 \mathrm{~mm}$ tube (Ta1, Ta3) with R123 and ethanol as working fluid have higher temperature and nearly constant, compare with $1.06 \mathrm{~mm}$ (Ta2, Ta4). This implies that the working fluid in vapor phase flows out from larger diameter tube in evaporator section. Nevertheless, adiabatic section of $2.03 \mathrm{~mm}$ tube with water as working fluid has higher temperature and severely fluctuate compare with $1.06 \mathrm{~mm}$ tube. The latent heat of evaporation $\left(\mathrm{h}_{\mathrm{fg}}\right)$ of water is higher than R123 and ethanol that result in lower evaporation. Moreover, the average temperature difference of adiabatic and evaporator section is about $4 \pm 1.5^{\circ} \mathrm{C}$. This value is smaller than those of ethanol and $\mathrm{R} 123$ as working fluid, which are $7 \pm 0.5$ and $10 \pm 0.9^{\circ} \mathrm{C}$, respectively. Water has higher surface tension and dynamic viscosity than ethanol and R123 resulting in water is difficult to circulate. Thus, higher vapor pressure is required for circulation. This causes the temperature of adiabatic section is higher. In case that it is difficult for the water to circulate, there appears the vapor flowing in opposite direction in some part of $1.06 \mathrm{~mm}$ diameter tube, it can be observed from high temperature ( $\mathrm{Ta} 2, \mathrm{Ta} 4)$ oscillation and has nearly temperature of $2.03 \mathrm{~mm}$ tube in adiabatic section. Macroscopically, CLOHP/NUD still has one direction circulation because it has no liquid flowed in $2.03 \mathrm{~mm}$ tube. Therefore, the temperature drop at this tube cannot be observed.

Effect of working fluids is shown in Fig. 6. This tendency occurs in all experiments at normal operation and this is in agreement with results from constant 2.03 $\mathrm{mm}$ inner diameter CLOHP, filling ratio $50 \%$ of total inner volume, 16 turns, $80^{\circ} \mathrm{C}$ of evaporator temperature, $20^{\circ} \mathrm{C}$ of condenser temperature and operated at vertical plan (Chareonsawan et al., 2003). The highest heat flux is obtained when using water as working. Due to its surface tension, $(\mathrm{dp} / \mathrm{dt})_{\text {sat }}$, sensible heat, latent heat and viscosity, were suitable for this operation. Although water cannot easily circulate, but latent heat and sensible heat of water is much higher than that of R123 and ethanol. Thus R123 can be easier evaporated in evaporator section result in more driving force of circulation and then more heat flux is obtained than using ethanol or water as working fluid.

Effect of length ratios: It was found from the experiments that, working fluid inside CLOHP/NUD still circulates in one direction. In Fig. 7 shows all of CLOHP/NUD operated at normal state, it can be concluded that, the heat flux increases when length ratio decrease. The decreasing in the length ratio means reducing the connection points, result in decreasing in pressure drop of sudden contraction. Thus, the working fluid circulates easily and continuously flows. Furthermore, length ratio lower than 1 presents that most of CLOHP/NUD is made of smaller diameter tube. In addition, the larger diameter tube not only supports working fluid to flow in one direction, also reduces flow friction of changing inner diameter of tubes. On the other hand, length ratio higher than 1 presents that most of CLOHP/NUD is made of larger 
diameter tube. Addition smaller diameter tube result in working fluid flows in one direction, flow friction increases in system.

Figure 8 shows that, heat flux tends to increase to its maximum and approach to heat flux of CLOHP (at very low length ratio). At 0.2 length ratio of CLOHP/NUD, critical state is occurred as shown in Fig. 9. The evaporator temperature is $100^{\circ} \mathrm{C}$ which equals to silicone oil temperature, it was implied that the dryout occurs. The CLOHP/NUD with 0.2 length ratio obtains heat transfer at $4.76 \mathrm{~kW} \mathrm{~m}^{-2}$ which it is lower than those of 0.33 length ratio, which has the highest heat transfer at $21.79 \mathrm{~kW} \mathrm{~m}$. Previously research of CLOHP (inner diameter $=1.06 \mathrm{~mm}, \mathrm{~L}_{\mathrm{e}}=\mathrm{L}_{\mathrm{a}}=\mathrm{L}_{\mathrm{c}}=$ $100 \mathrm{~mm}, 15$ turns, filling ratio $50 \%, \mathrm{WF}=$ Water, vertical orientation) showed that, the highest heat flux of CLOHP is $1.6 \mathrm{~kW} \mathrm{~m}^{-2}$ (Sakulchangsatjatai et al., 2007). This shows that, CLOHP/NUD with length ratio closed to zero was the same in heat flux and phenomena as CLOHP. In contrast, heat flux decreases when length ratio increases as shown in Fig. 8. Heat flux of CLOHP/NUD with 3 length ratio is not different compare with that of CLOHP/NUD with length ratio of 1 , but still higher than CLOHP (inner diameter = $2.03 \mathrm{~mm}, \mathrm{~L}_{\mathrm{e}}=\mathrm{L}_{\mathrm{a}}=\mathrm{L}_{\mathrm{c}}=100 \mathrm{~mm}, 15$ turns, filling ratio $50 \%, \mathrm{WF}=$ water, vertical orientation). This can be concluded that, heat flux of CLOHP/NUD is higher than heat flux of CLOHP as also found in previous researches (Liu et al., 2007; Tharawadee et al., 2008).

\section{CONCLUSION}

The effects of length ratios and working fluids on the heat performance of CLOHP/NUD have been experimentally investigated. The following main conclusions can be drawn from the study:

- The working fluid of the CLOHP/NUD with length ratio of $3,1,0.33$ and 0.2 flows in one direction. The heat flux is increased when the length ratio decreases

- Type of working fluid affects its circulation direction. Heat flux of CLOHP/NUD with water as working fluid reaches the highest at $21.79 \mathrm{~kW} \mathrm{~m}^{-2}$ at vertical orientation. The CLOHP/NUD with R123 as working fluid obtains the heat flux at $20.85 \mathrm{~kW} \mathrm{~m}^{-2}$ with length ratio of 0.2 at vertical orientation. The CLOHP/NUD with ethanol as working fluid obtains the heat flux of $14.41 \mathrm{~kW} \mathrm{~m}^{-2}$ with length ratio of 0.33 at vertical orientation
The heat transfer performance of CLOHP/NUD can be improved if one directional circulation of working fluid can be controlled.

\section{ACKNOWLEDGEMENT}

This research work was conducted under the Thailand Research Fund (under Contact No. MRG5180325). The authors would like to express their sincere appreciation for all of the support provided.

\section{REFERENCES}

Akachi, H., F. Polasek and P. Stulc, 1996. Pulsating heat pipe. Proceedings of the 5th International Heat Pipe Symposium, Melbourne Australia, pp: 208-217.

Chareonsawan, P., S. Khandekar, M. Groll and P. Terdtoon, 2003. Closed-loop pulsating heat pipe part A: Parametric experimental investigations. Applied Therm. Eng., 23: 2009-2020. DOI: 10.1016/S1359-4311(03)00159-5

Khandekar, S. and M. Groll, 2004. An insight into thermo-hydrodynamic coupling in closed-loop pulsating heat pipes. J. Therm. Sci., 43: 13-24. DOI: 10.1016/S1290-0729(03)00100-5

Liu, S., J. Li, X. Dong and H. Chen, 2007. Experimental study of flow patterns and improved configurations for pulsating heat pipes. J. Therm. Sci., 16: 56-62. DOI: 10.1016/S03019322(01)00037-4

Rittidech, S., N. Pipatpaiboon and P. Terdtoon, 2007. Heat transfer characteristics of a closed-loop oscillating heat pipe with check valve. Applied Energy, 84: 565-577. DOI: 10.1016/J.APENERGY.2006.09.010

Sakulchangsatjatai, P., N. Kammuang-Lue, P. Terdtoon and D.J. Mook, 2007. Effect of geometrical sizes on critical heat flux of a vertical closed-loop pulsating heat pipe. Proceeding of the 14th International Heat Pipe Conference, Florianopolis, Brazil, pp: 252-257.

Tharawadee, N., P. Sakulchangsatjatai and P. Terdtoon, 2008. Effect of diameter ratio heat transfer characteristic of non-uniform diameter closed loop oscillating heat pipe. Proceedings of the 9th International Heat Pipe Symposium, Kuala Lumpur, Malaysia, pp: 148-153. 